Research Article

\title{
The Friction of Saline Ice on Aluminium
}

\author{
Christopher Wallen-Russell ${ }^{1}$ and Ben Lishman ${ }^{1,2}$ \\ ${ }^{1}$ Institute for Risk and Disaster Reduction, University College London, Gower Street, London WC1E6BT, UK \\ ${ }^{2}$ Department of Engineering, Portsmouth University, Anglesea Building, Anglesea Road, Portsmouth PO13DJ, UK \\ Correspondence should be addressed to Ben Lishman; b.lishman@ucl.ac.uk
}

Received 29 October 2015; Revised 29 February 2016; Accepted 23 March 2016

Academic Editor: Meng Hua

Copyright (C) 2016 C. Wallen-Russell and B. Lishman. This is an open access article distributed under the Creative Commons Attribution License, which permits unrestricted use, distribution, and reproduction in any medium, provided the original work is properly cited.

\begin{abstract}
The friction of ice on other materials controls loading on offshore structures and vessels in the Arctic. However, ice friction is complicated, because ice in nature exists near to its melting point. Frictional heating can cause local softening and perhaps melting and lubrication, thus affecting the friction and creating a feedback loop. Ice friction is therefore likely to depend on sliding speed and sliding history, as well as bulk temperature. The roughness of the sliding materials may also affect the friction. Here we present results of a series of laboratory experiments, sliding saline ice on aluminium, and controlling for roughness and temperature. We find that the friction of saline ice on aluminium $\mu_{\text {ice-al }}=0.1$ typically, but that this value varies with sliding conditions. We propose physical models which explain the variations in sliding friction.
\end{abstract}

\section{Introduction}

Studies of the mechanisms behind the friction of ice affect a range of research areas, including winter sports [1], Arctic shipping and offshore structure design [2,3], vehicle design for ice road conditions [4], and glacier advance [5]. The ability to predict (and perhaps control) ice friction therefore has economic value and can improve our understanding of the cryosphere.

Ice friction is more difficult to model than dry friction, since the work done against friction releases heat, which softens and sometimes melts the ice surface, changing the friction coefficient and creating a feedback loop. A number of recent studies have shown that the friction of ice on ice depends on temperature, on the speed of sliding, and also on the history of sliding but is independent of normal load [6-8]. Models of the friction of ice on ice incorporate the ice hardness, the thermal properties of the ice, and assumptions about the nature of the asperity-asperity contacts which govern dry friction $[7,9,10]$.

In this paper we investigate how the friction of sea ice on aluminium varies with temperature, surface roughness, sliding speed, and sliding history. We aim to improve the understanding of the nature of ice friction, and we choose aluminium as our secondary material for two reasons. First, aluminium and its alloys are used in ships (e.g., the S. V Polaris, an aluminium-hulled vessel which has overwintered in the Arctic), offshore structures, and other salt-watersensitive coastal structures, but its friction on ice has not been studied (unlike, e.g., steel and concrete [11-13]). The ISO standard for Arctic Offshore Structures (ISO19906, [14]) contains information on the friction of ice on steel and concrete but not on other materials, so this research may add to the knowledge base for Arctic practitioners. Aluminium is also used to make experimental equipment for research on sea ice [15] and its friction here is needed to interpret other results. Secondly, aluminium is significantly harder and more thermally conductive than ice and thus provides a useful comparison to more conventional ice-ice sliding friction. Models of ice friction rely on comparisons between different materials to distinguish the importance of various material properties [9] and so new experimental results, on previously unstudied materials, can provide supporting evidence for theories of ice friction.

\section{Materials and Methods}

2.1. Ice Preparation. Discs of vertically orientated columnar saline ice were grown in insulated $(20 \mathrm{~cm}$ thick polystyrene) 


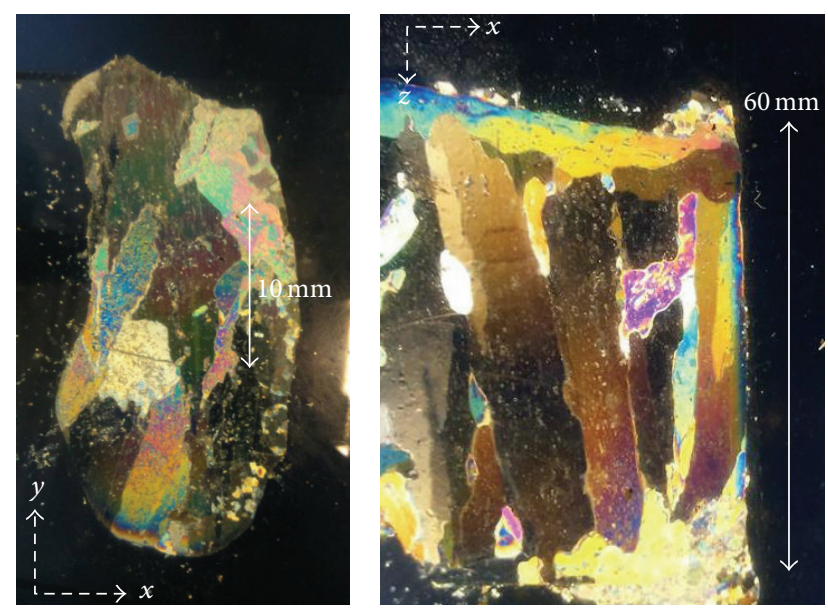

Figure 1: Ice thin sections in the $x-y$ plane and in the $x$ - $z$ plane, showing a columnar structure.

acrylic cylindrical tanks in the Rock and Ice Physics cold room facilities at UCL. Discs were grown to $\sim 100-110 \mathrm{~mm}$ in depth with an air temperature of $-10^{\circ} \mathrm{C}[6,16]$. The ice had typical grain dimensions $10 \mathrm{~mm}$ in the horizontal $(x-y)$ plane and $50 \mathrm{~mm}$ in the vertical $(z)$ direction. The insulation meant that only the upper surface of the ice was exposed to the cold environment, leading to unidirectional cooling like that observed in natural sea ice growth. Heating elements underneath the tanks kept the saline water reservoir around $-2^{\circ} \mathrm{C}$. The ice was frozen from a mixture of water and $33 \mathrm{~g} / \mathrm{L}$ salt, leading to bulk ice salinity close to $8 \mathrm{ppt}$. Thin sections of the ice, showing the crystal structure, are shown in Figure 1. Oblong blocks of dimensions $240 \mathrm{~mm} \times 90 \mathrm{~mm} \times 90 \mathrm{~mm}$ were cut using a bandsaw. These blocks were then refined on a mill to give two pairs of polished parallel surfaces.

2.2. Experimental Setup. Figure 2 shows the experimental setup: a double shear configuration, with the central slider block made out of saline ice, flanked on either side by aluminium blocks sitting on pedestals. A hydraulic load frame (the black frame in Figure 2) is used to create a side load (also called the normal load), and a hydraulic actuator provides the load to slide the central block between the aluminium ones. This is also referred to as a shear load. The instantaneous coefficient of friction is then given by the shear load divided by twice the normal load (since the normal load acts on two faces). The entire load frame with blocks sits in an environmental chamber to allow the temperature to be controlled.

Two types of experiments were performed: "hold time" and "staggered speed." These experiments allow us to understand how static friction evolves and how dynamic friction changes with sliding speed. Overall, 16 "hold time" experiments were conducted under different conditions and 22 "staggered speed" experiments.

2.2.1. Hold Time Tests. For "hold time" tests, the central ice block is moved at constant speed $\left(5 \times 10^{-4} \mathrm{~ms}^{-1}\right)$ for $20 \mathrm{~s}$, interspersed with periods where the block is not moved. Typically, the longer the block is left static, the greater the force required to restart motion is. In these experiments we investigate the effects of holding for $1 \mathrm{~s}, 10 \mathrm{~s}, 100 \mathrm{~s}$, and $1000 \mathrm{~s}$. The static friction is then given as the maximum measured friction during the higher loading which occurs after reinitiating movement.

2.2.2. Staggered Speed Tests. The central ice block is slid past the aluminium blocks at velocities of $1 \times 10^{-6} \mathrm{~ms}^{-1}, 1 \times$ $10^{-5} \mathrm{~ms}^{-1}, 1 \times 10^{-4} \mathrm{~ms}^{-1}, 1 \times 10^{-3} \mathrm{~ms}^{-1}$, and $1 \times 10^{-2} \mathrm{~ms}^{-1}$ consecutively, for $100 \mathrm{~s}$ each. Friction is averaged over the period during which sliding is in steady-state (or across stick-slip cycles, discussed below).

Typical friction series for two different sliding speeds and for a hold time test are shown in Figure 3. Stick-slip behaviour is clearly seen at a sliding speed of $1 \times 10^{-4} \mathrm{~ms}^{-1}$ in Figure 3(a).

In total, 5 ice blocks were used. We observed no correlation between results and the number of times a block was used. Normal/side load is applied shortly $(<10 \mathrm{~s})$ before the start of experiments. All loads and displacements are logged at intervals of less than $100 \mathrm{~ms}$ using load cells and displacement transducers which have been externally calibrated before use.

The aluminium blocks were polished with two different grades of abrasive paper on two sides to give two controlled types of roughness. The "polished" aluminium was scrubbed with silicon carbide waterproof electrocoated abrasive paper of roughness CW-600. "Rough" aluminium was hand scrubbed with abrasive paper of P120 roughness. The blocks had dimensions of $300 \times 100 \times 100 \mathrm{~mm}$. Depending on the desired conditions of the experiment, the aluminium blocks were rotated to have either "rough" or "polished" sides in contact with the central sliding ice block. In all experiments, the direction of sliding of the ice was perpendicular to the columnar ice grains (cf. [10]).

\section{Results}

We run hold time tests and staggered speed tests for two different temperatures $\left(-2^{\circ} \mathrm{C}\right.$ and $\left.-10^{\circ} \mathrm{C}\right)$ and two different types of aluminium roughness. The (time-varying) friction coefficient was calculated as the shear load divided by twice the normal load (since friction occurs over two separate contact planes). Side loads throughout were approximately $1 \mathrm{kN}$, applied with a lockable manual hydraulic pump. The normal load was observed to decrease during experiments, probably because of a slight leak of hydraulic oil. This decrease was never greater than $10 \%$ of the original normal load and was accounted for in the results presented.

\subsection{Hold Time Experiments}

3.1.1. Effect of Varying Aluminium Roughness. Figure 4 shows a comparison of the effects of hold time on polished and rough aluminium at $-2^{\circ} \mathrm{C}$. Figure 5 shows the same comparison at $-10^{\circ} \mathrm{C}$. Markers on the plots are equivalent to the markers shown in Figure 3(c). The lines represent logarithmic best fits and allow comparison with other hold time experiments $[6,10]$. At $-2^{\circ} \mathrm{C}$, the roughness of the surface has a clear effect on the coefficient of static friction: the static friction on 


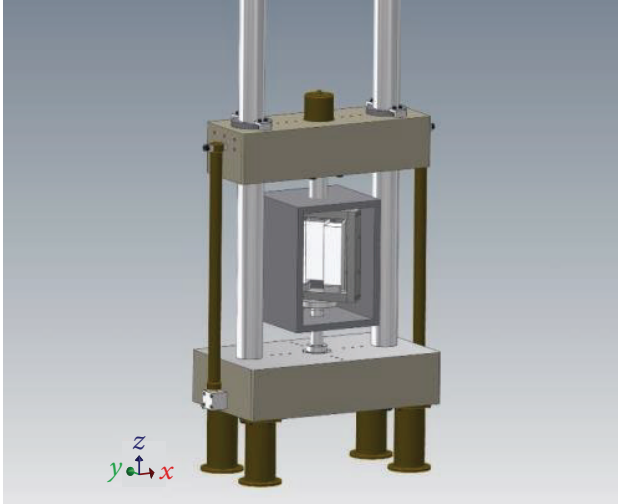

(a)

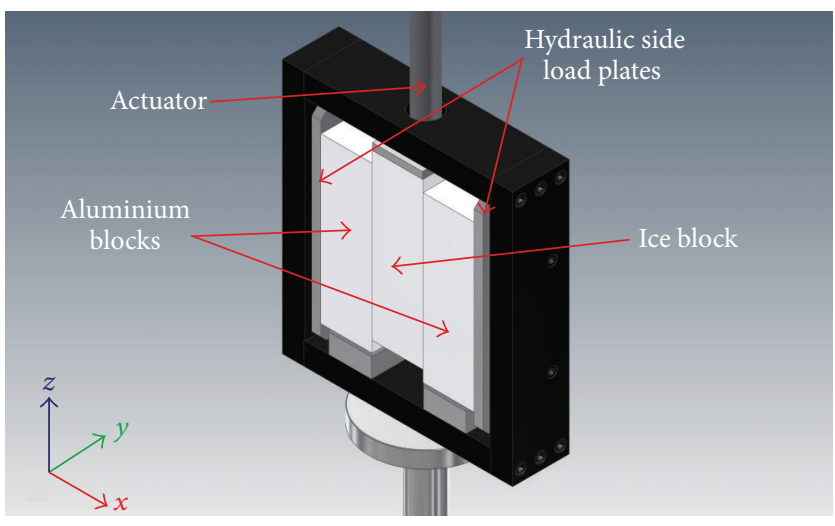

(b)

FIGURE 2: (a) shows the loading apparatus, comprising a 20 T uniaxial compression rig, an environmental chamber, and a shear loading frame; (b) shows a close-up of the shear load frame.

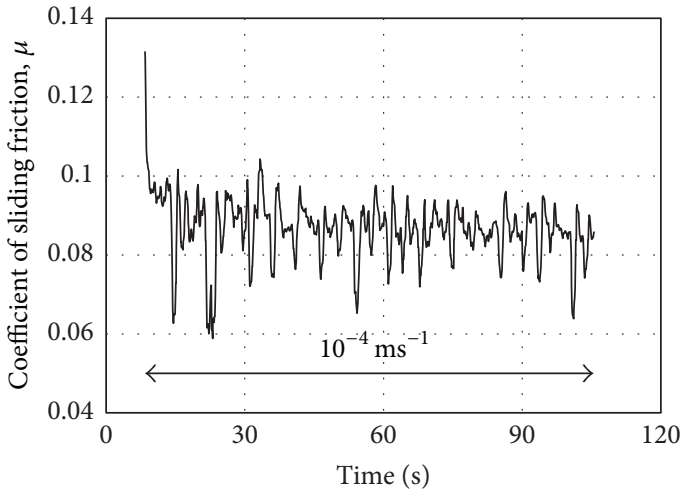

(a)

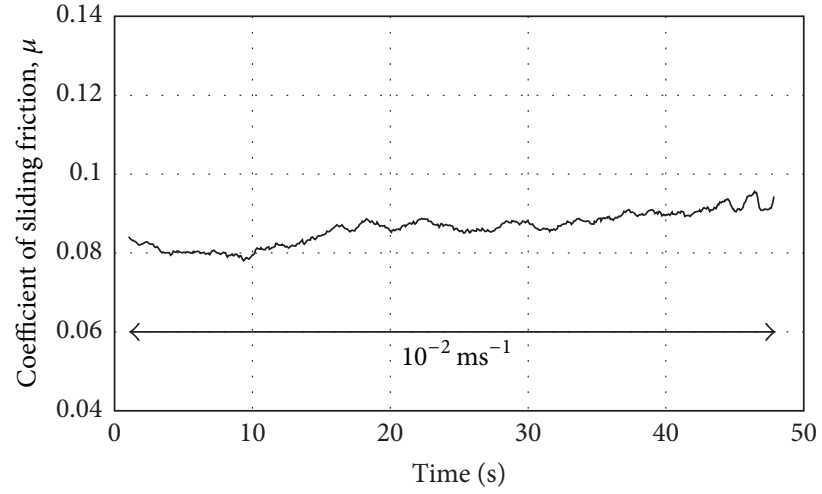

(b)

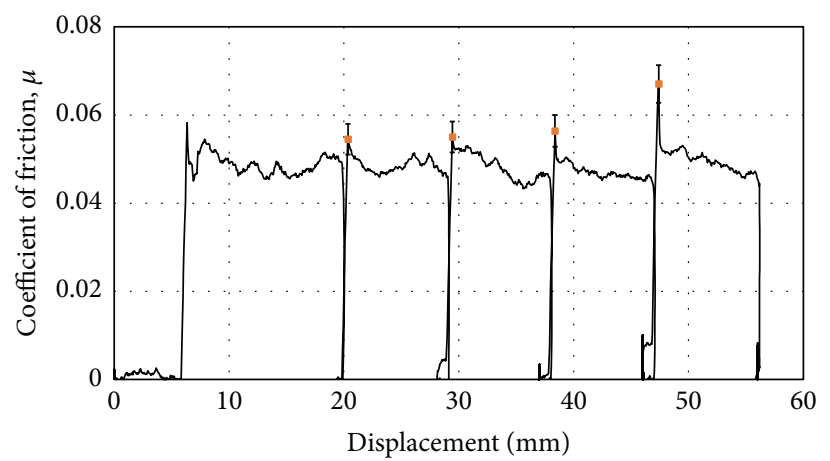

(c)

FIgURE 3: Example plots showing variations in the coefficient of friction. (a) Friction against time, $v_{s}=10^{-4} \mathrm{~ms}^{-1}$, rough aluminium at $-2^{\circ} \mathrm{C}$; (b) friction against time, $v_{s}=10^{-2} \mathrm{~ms}^{-1}$, rough aluminium at $-2^{\circ} \mathrm{C}$; (c) friction against displacement from a typical hold time test $\left(-2^{\circ} \mathrm{C}\right.$, polished aluminium). Increases in static friction following periods of static contact are clear at 20, 29, 38, and $47 \mathrm{~mm}$ of displacement and are marked on the plot.

the rougher surface is approximately double that on the smoother surface. At $-10^{\circ} \mathrm{C}$, no such difference is observed: the behaviour is almost independent of aluminium roughness.

3.1.2. Effect of Varying Temperature. In Figures 6 and 7 we replot the data from Figures 4 and 5 to show the effects of varying temperature. Figure 6 shows a comparison of friction on polished aluminium at $-10^{\circ} \mathrm{C}$ and $-2^{\circ} \mathrm{C}$, and it is clear from this figure that static friction is higher at lower temperatures. Figure 7 shows a similar comparison for rough aluminium. Here the effects of varying temperature are less pronounced, but the static friction is still higher at lower temperatures. 


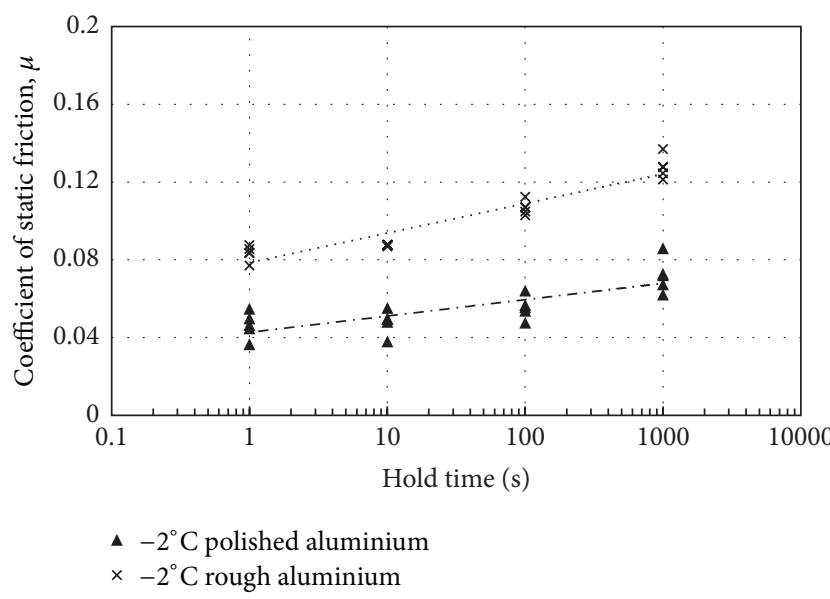

FIgURE 4: Friction as a function of hold time for experiments involving rough (crosses) and polished aluminium (triangles) at $-2^{\circ} \mathrm{C}$. Individual data points represent separate experiments, and the lines represent logarithmic best fits.

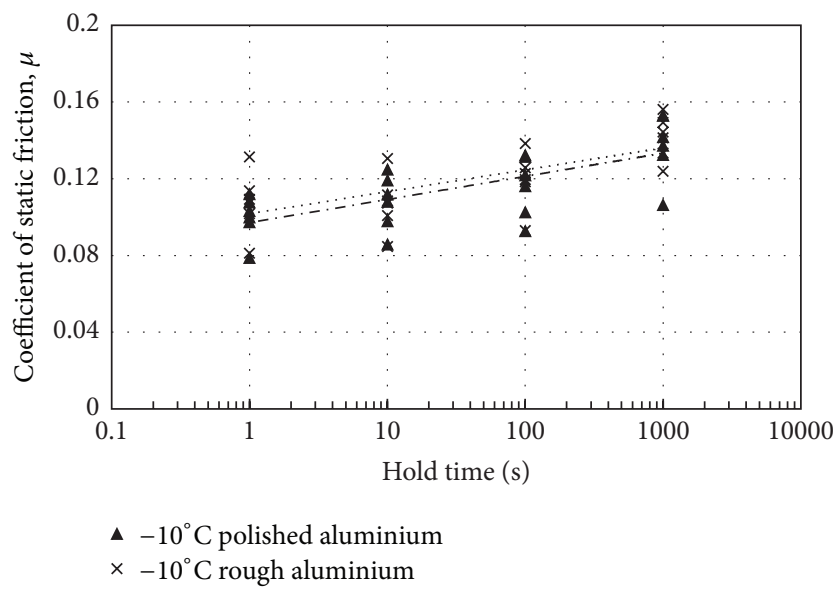

FIGURE 5: Friction as a function of hold time for experiments involving rough and polished aluminium at $-10^{\circ} \mathrm{C}$. Individual data points represent separate experiments, and the lines represent logarithmic best fits.

With different types of roughness and temperatures, the effect of hold time on static friction changes (hence the different slopes on our fitted straight lines). This behaviour can be quantified, as described by Schulson [17]. First, no effect of increasing hold time is observed until some threshold period $t_{t}$. After this threshold period, static friction $\mu_{s}$ increases with the logarithm of holding time $t_{h}$ until some limit of shear strength is reached. This is described by the relationship

$$
\Delta \mu=\beta \log _{10}\left(\frac{t_{h}}{t_{t}}\right),
$$

where $\Delta \mu$ is the difference between the peak static friction $\mu_{s}$ and the steady state sliding friction. The threshold period $t_{t}$ is found to be $0.06 \mathrm{~s}$ for our experiments [17]. At $-10^{\circ} \mathrm{C}$, $\beta=0.3 \pm 0.03$ for the friction of ice on ice [17]. Table 1 gives equivalent values for our experiments.

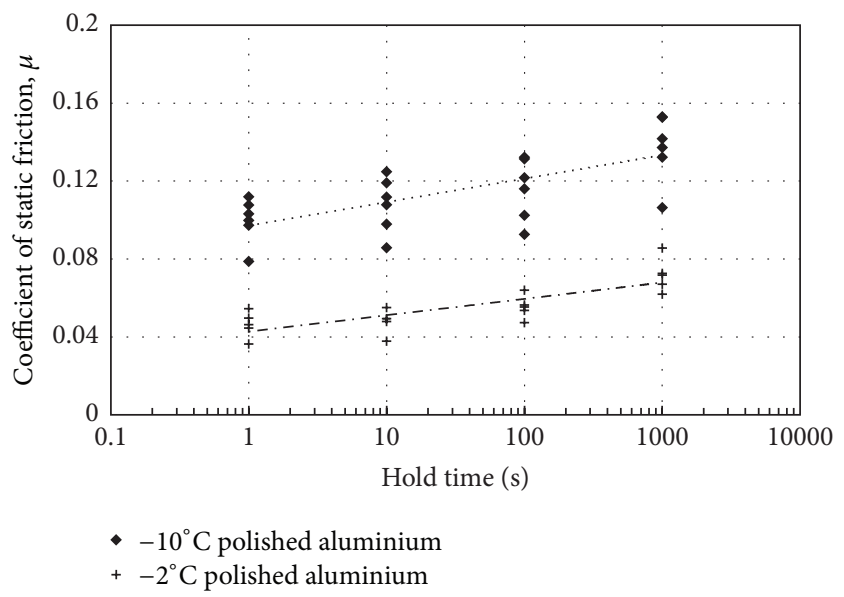

Figure 6: Friction as a function of hold time for experiments involving polished aluminium, comparing $-2^{\circ} \mathrm{C}(+)$ and $-10^{\circ} \mathrm{C}$ (diamonds). A logarithmic line of best fit is fitted to the average results. The data compared here are also shown separately in Figures 4 and 5.

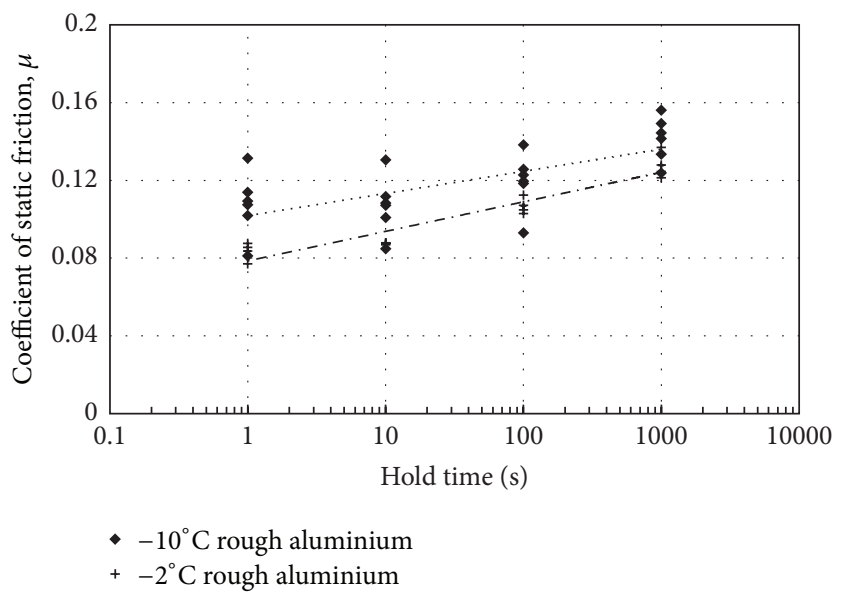

FIGURE 7: Friction as a function of hold time for experiments involving rough aluminium, comparing $-2^{\circ} \mathrm{C}(+)$ and $-10^{\circ} \mathrm{C}$ (diamonds). A logarithmic line of best fit is fitted to the average results. The data compared here are also shown separately in Figures 4 and 5.

TABLE 1: Values of $\beta$, which gives the rate of increase of static friction, as a function of temperature and aluminium roughness.

\begin{tabular}{lcc}
\hline Temperature $/{ }^{\circ} \mathrm{C}$ & Polished/rough Al & $\beta \times 10^{3}$ \\
\hline-2 & Polished & 6.4 \\
-2 & Rough & 12.3 \\
-10 & Polished & 8.5 \\
-10 & Rough & 10.7 \\
\hline
\end{tabular}

These values of $\beta$ are significantly lower than those for ice on ice: this tells us that static friction increases more slowly in ice-aluminium sliding than ice-ice sliding. This can be observed from, for example, [6], where static friction rises as high as 1 after $1000 \mathrm{~s}$. We also note that although the log-linear relation between friction and hold time is a useful approximation, it is not necessarily descriptive of reality. In each set 


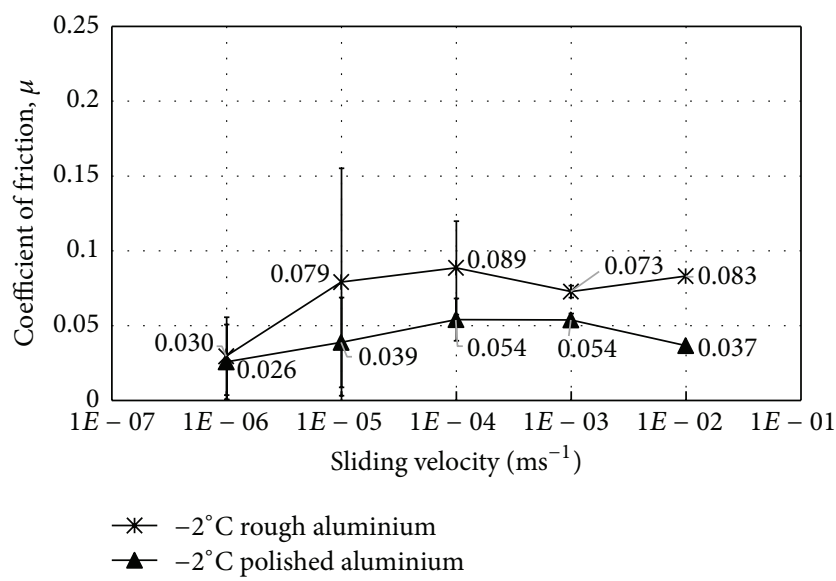

Figure 8: Friction as a function of sliding speed for ice on aluminium, showing results for rough and polished aluminium at $-2^{\circ} \mathrm{C}$.

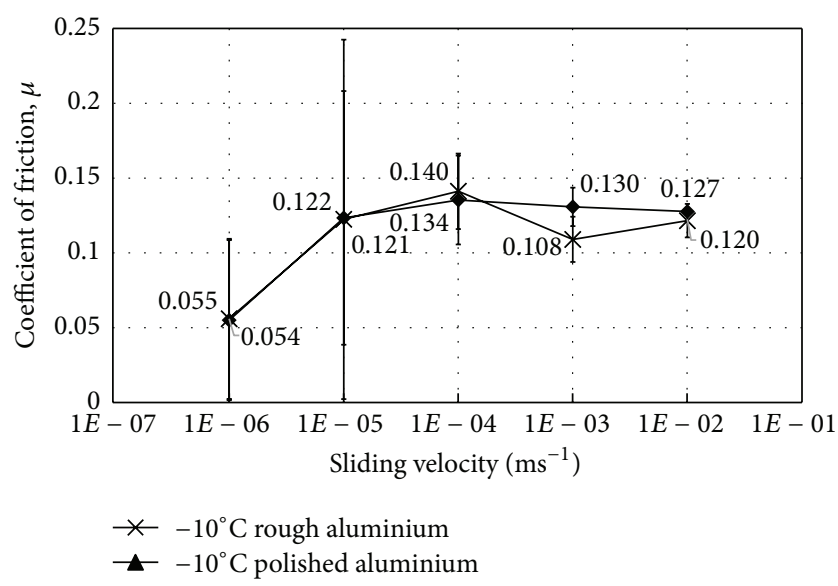

FIGURE 9: Friction as a function of sliding speed for ice on aluminium, showing results for rough and polished aluminium at $-10^{\circ} \mathrm{C}$.

of hold time results shown here, the average value for friction after $10 \mathrm{~s}$ hold falls below the log-linear best fit line, suggesting that the true relationship curves upwards (in log-linear space) with hold time. Finally, we note that these results are limited to static hold times up to $1000 \mathrm{~s}$ and may not be valid for longer contact times. One limit is clear: the frictional strength of the contact cannot be greater than the shear strength of the ice, or the ice would fail in shear rather than frictional sliding.

3.2. Staggered Speed Experiments. Figures 8-11 show the friction of ice on aluminium measured during our staggered speed experiments, as described above. Stick-slip type behaviour, in which loads cyclically build up and then collapse as the ice block moves, was observed in many of the low speed $\left(v_{s} \leq 10^{-4} \mathrm{~ms}^{-1}\right)$ experiments. The vertical bars on data points represent the extent of the largest stick-slip deviation from the mean (typically the stick-slip cycles are approximately symmetric about the mean), while the main marker represents the time-averaged force. At higher speeds, sliding is smoother.

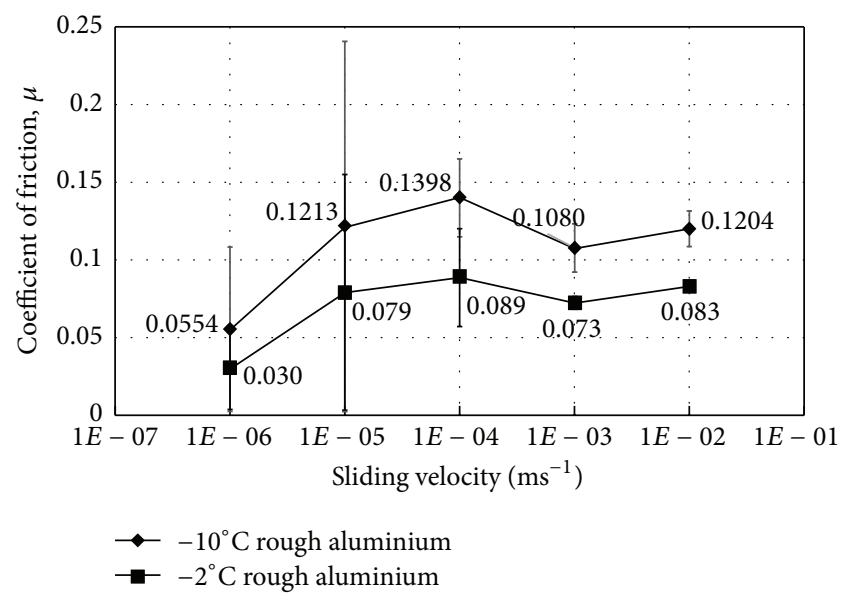

FIgURE 10: Friction as a function of sliding speed for ice on aluminium, showing results for rough aluminium at $-10^{\circ} \mathrm{C}$ and $-2^{\circ} \mathrm{C}$. The data compared here are also shown separately in Figures 8 and 9.

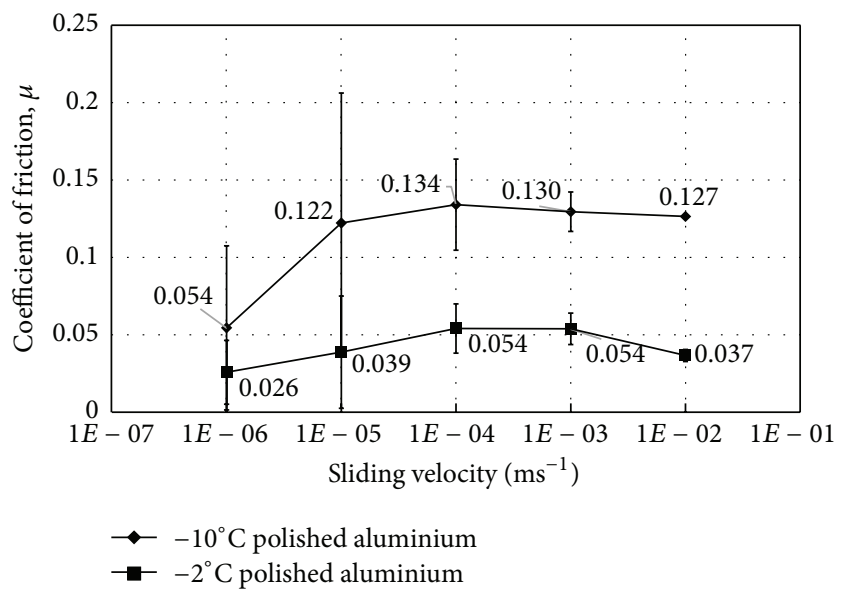

FIgURE 11: Friction as a function of sliding speed for ice on aluminium, showing results for polished aluminium at $-10^{\circ} \mathrm{C}$ and $-2^{\circ} \mathrm{C}$. The data compared here are also shown separately in Figures 8 and 9.

3.2.1. Effect of Varying Aluminium Roughness. Figure 8 shows the dynamic friction coefficient of ice against rough and polished aluminium at $-2^{\circ} \mathrm{C}$. Friction (as a function of sliding speed) peaks around $10^{-4} \mathrm{~ms}^{-1}$ and is higher on rough aluminium than on smooth aluminium. Figure 9 shows the same experiments at $-10^{\circ} \mathrm{C}$. Again, friction is highest around $10^{-4} \mathrm{~ms}^{-1}$, but here the roughness of the aluminium has little effect on the sliding friction.

3.2.2. Effect of Varying Temperature. In Figures 10 and 11 we replot the data from Figures 8 and 9 to show the effects of varying temperature. We find, for both rough and smooth aluminium, that dynamic friction is higher at $-10^{\circ} \mathrm{C}$ than at $-2^{\circ} \mathrm{C}$.

\section{Discussion}

The results presented above demonstrate several general principles. 
The Friction Coefficient of Ice on Aluminium Is around 0.1. This observation appears to hold broadly. In many applications, the roughness, temperature, sliding speed, and sliding history are not known, or a single figure is needed to cover a range of conditions. For simplicity, in such situations, we recommend that $\mu=0.1$. If higher friction values are more conservative (which may not always be the case) and a conservative value for friction is needed, then a choice of $\mu=0.2$ would encompass all of our results.

The Dynamic Friction of Ice on Aluminium Is Qualitatively Similar to the Friction of Ice on Ice. At very low speeds, ice friction increases with increasing speed. In this regime frictional heating plays a minimal role. Interlocking asperities on the ice surface resist sliding and must be sheared or deformed. When the slip rate increases, dislocations have less time to align, and so the asperities are stronger and friction is correspondingly higher [17]. At some speed peak friction is reached. Above this speed, the energy of friction warms the ice, which causes it to soften and may lead to lubrication at the sliding interface and also at grain boundaries near the sliding interface. In this regime, increasing the sliding speed leads to more energy dissipation, more softening or melt, and hence lower friction [6]. This behaviour has been repeatedly observed in ice-ice friction $[6-8,18]$, and here we see similar behaviour in the friction of ice on aluminium.

In all our experiments we measure maximum friction at sliding speeds of $10^{-4} \mathrm{~ms}^{-1}$, which suggests that maximum friction occurs between $10^{-5}$ and $10^{-3} \mathrm{~ms}^{-1}$.

Static Friction between Ice and Aluminium Increases with Contact Time. If an interface is left under normal loading for some length of time, then the force required to reinitiate movement increases with the log of contact time. The mechanism which causes this is that asperities creep over time, becoming broader, and increasing the true contact area. This increased true contact area leads to increased friction [10].

Our static friction results are quantified by the parameter $\beta$, which measures the extent to which friction increases with the log of contact time (this is equivalent to the slope of the best-fit lines on the graphs under "hold time experiments"). In experiments measuring the friction of ice on ice, $\beta$ was found to be around 0.3 , and $\beta$ has been shown to be around 0.1 for the friction of ice on steel and ice on PMMA (plexiglass) [19]. Our measured values for $\beta$ are significantly lower, around 0.01: we find that even $1000 \mathrm{~s}$ hold (around quarter of an hour) leads to an increase in friction of less than 0.1 . Similar hold times for ice-ice friction lead to static friction which is higher than kinetic friction by $0.5-1$. Healing and strengthening in our experiments are considerably lower than in comparable experiments with other materials. One possible explanation for this is that aluminium, which has a high thermal conductivity $\left(\sim 200 \mathrm{Wm}^{-1} \mathrm{~K}^{-1}\right.$, compared to $\sim 20 \mathrm{Wm}^{-1} \mathrm{~K}^{-1}$ for steel, $\sim 2 \mathrm{Wm}^{-1} \mathrm{~K}^{-1}$ for ice, and $\sim$ $0.2 \mathrm{Wm}^{-1} \mathrm{~K}^{-1}$ for PMMA), conducts heat away from the sliding interface more quickly, and thus the contacting asperities are colder and deform less under normal load.
Friction Is Higher at $-10^{\circ} \mathrm{C}$ than at $-2^{\circ} \mathrm{C}$. This is perhaps not surprising: at $-2^{\circ} \mathrm{C}$ more softening occurs and melting is more likely, so the higher temperature leads to lower friction.

The Importance of Roughness Is More Pronounced at $-2^{\circ} \mathrm{C}$ than at $-10^{\circ} \mathrm{C}$. In both our hold time experiments and our staggered-speed experiments, rough aluminium leads to markedly higher friction than polished aluminium at $-2^{\circ} \mathrm{C}$ but roughness has little effect at $-10^{\circ} \mathrm{C}$. This may be related to softening effects. The rougher material has larger asperities (this is what causes roughness). At temperatures close to melting, these asperities in the harder material (aluminium) indent the softer material (ice) and cause a high true contact area, leading to higher friction. At lower temperatures, the ice is less ductile, so indentation may be lower and true contact area (and friction) less affected by the roughness of the aluminium. We note here that ice, as the softer material, is abraded more quickly, and so the initial roughness of the ice is less likely to affect the steady-state friction [20].

Critical Slip. Critical slip is a measurement of the duration of the effects of static friction [21]. The friction decays with sliding, from the peak static friction to the steady-state kinetic sliding friction, and critical slip defines the point at which friction is equal to kinetic friction plus $1 / e$ of this range. Here we use only one sliding speed in our hold time experiments, so we are unable to determine whether critical slip is better represented as a time or a distance: on average it occurs over $1.57 \mathrm{~mm}$ or $3.36 \mathrm{~s}$, which is in good agreement with the critical slip time of 3 s reported in Lishman et al. [21].

Stick-Slip Friction. Stick-slip friction was frequently observed, particularly during experiments at $10^{-4} \mathrm{~ms}^{-1}$ or less (see Figure 3). Stick-slip is usually understood as a system property and depends on the stiffness of the actuator system [19, 22]. Forces rise as the sliding block remains stationary and elastic energy is built up in the actuator. At some stage these forces are sufficient to overcome the static friction, leading to dynamic sliding with lower friction and a relaxation of the actuator. This pattern repeats cyclically. At speeds measured in $\mathrm{mms}^{-1}$ and $\mathrm{cms}^{-1}$ we do not see stick-slip, so it seems that stick-slip behaviour is more likely to be seen in controlled laboratory experiments than in faster-moving sliding in the Arctic.

\section{Conclusions}

The friction of ice on aluminium is qualitatively similar to the friction of ice on ice: it shows slip-rate-strengthening at low speeds, where frictional warming is negligible, and slip-rateweakening at high speeds once warming leads to softening of the ice (and possible increased lubrication). Further, static friction is higher than dynamic friction, probably due to creep of asperities during static contact. Static friction increases more slowly (i.e., increases less with hold time) for ice on aluminium than for ice on ice, ice on steel, or ice on PMMA (plexiglass). Friction varies with temperature and with roughness of the harder material, as predicted by intuitive models. 
Stick-slip friction was observed between sea ice and aluminium. These results may inform experiments where ice interacts with aluminium and may also prove useful to Arctic designers and practitioners. Further, the results show that the aluminium roughness affects the friction, particularly at temperatures close to melting: this result is likely to remain true for ice sliding on other metals and relatively hard materials. In cases where one number is needed to represent $\mu_{\text {ice-al }}$, the friction of ice on aluminium, we recommend a value of $\mu=0.1$.

\section{Competing Interests}

The authors declare that they have no competing interests.

\section{References}

[1] P. A. Federolf, R. Mills, and B. Nigg, "Ice friction of flared ice hockey skate blades," Journal of Sports Sciences, vol. 26, no. 11, pp. 1201-1208, 2008.

[2] I. Metrikin, S. Løset, N. A. Jenssen, and S. Kerkeni, "Numerical simulation of dynamic positioning in ice," Marine Technology Society Journal, vol. 47, no. 2, pp. 14-30, 2013.

[3] L. Zhou, K. Riska, T. Moan, and B. Su, "Numerical modeling of ice loads on an icebreaking tanker: comparing simulations with model tests," Cold Regions Science and Technology, vol. 87, pp. 33-46, 2013.

[4] S. Ella, P.-Y. Formagne, V. Koutsos, and J. R. Blackford, "Investigation of rubber friction on snow for tyres," Tribology International, vol. 59, pp. 292-301, 2013.

[5] J. Faillettaz, D. Sornette, and M. Funk, "Numerical modeling of a gravity-driven instability of a cold hanging glacier: reanalysis of the 1895 break-off of Altelsgletscher, Switzerland," Journal of Glaciology, vol. 57, no. 205, pp. 817-831, 2011.

[6] B. Lishman, P. Sammonds, and D. Feltham, "A rate and state friction law for saline ice," Journal of Geophysical Research: Oceans, vol. 116, no. 5, Article ID C05011, 2011.

[7] E. M. Schulson and A. L. Fortt, "Friction of ice on ice," Journal of Geophysical Research: Solid Earth, vol. 117, no. 12, 2012.

[8] S. Sukhorukov and S. Løset, "Friction of sea ice on sea ice," Cold Regions Science and Technology, vol. 94, pp. 1-12, 2013.

[9] L. Makkonen and M. Tikanmäki, "Modeling the friction of ice," Cold Regions Science and Technology, vol. 102, pp. 84-93, 2014.

[10] E. M. Schulson and A. L. Fortt, "Static strengthening of frictional surfaces of ice," Acta Materialia, vol. 61, no. 5, pp. 16161623, 2013.

[11] H. Saeki, T. Ono, N. Nakazawa, M. Sakai, and S. Tanaka, “The coefficient of friction between sea ice and various materials used in offshore structures," Journal of Energy Resources Technology, vol. 108, no. 1, pp. 65-71, 1986.

[12] R. J. Frederking and A. Barker, "Friction of sea ice on steel for condition of varying speeds," in Proceedings of the Twelfth International Offshore and Polar Engineering Conference, International Society of Offshore and Polar Engineers, Kitakyushu, Japan, May 2002.

[13] B. Fiorio, J. Meyssonnier, and M. Boulon, "Experimental study of the friction of ice over concrete under simplified ice-structure interaction conditions," Canadian Journal of Civil Engineering, vol. 29, no. 3, pp. 347-359, 2002.

[14] International Standards Organisation, "Petroleum and natural gas industries-arctic offshore structures," ISO 19906, International Standards Organisation, 2010.
[15] R. Gagnon, "First lab tests of the Blade Runners concept for reducing ice induced vibration of structures," in Proceedings of the 22nd IAHR Internation Symposium on Ice, Singapore, August 2014.

[16] E. Bailey, P. R. Sammonds, and D. L. Feltham, "The consolidation and bond strength of rafted sea ice," Cold Regions Science and Technology, vol. 83-84, pp. 37-48, 2012.

[17] E. M. Schulson, "Low-speed friction and brittle compressive failure of ice: fundamental processes in ice mechanics," International Materials Reviews, vol. 60, no. 8, pp. 451-478, 2016.

[18] N. Maeno, M. Arakawa, A. Yasutome, N. Mizukami, and S. Kanazawa, "Ice-ice friction measurements, and water lubrication and adhesion-shear mechanisms," Canadian Journal of Physics, vol. 81, no. 1-2, pp. 241-249, 2003.

[19] J. R. Blackford, G. Skouvaklis, M. Purser, and V. Koutsos, "Friction on ice: stick and slip," Faraday Discussions, vol. 156, pp. 243-254, 2012.

[20] D. C. Hatton, P. R. Sammonds, and D. L. Feltham, "Ice internal friction: Standard theoretical perspectives on friction codified, adapted for the unusual rheology of ice, and unified," Philosophical Magazine, vol. 89, no. 31, pp. 2771-2799, 2009.

[21] B. Lishman, P. R. Sammonds, and D. L. Feltham, "Critical slip and time dependence in sea ice friction," Cold Regions Science and Technology, vol. 90-91, pp. 9-13, 2013.

[22] M. Beeman, W. B. Durham, and S. H. Kirby, "Friction of ice," Journal of Geophysical Research: Solid Earth, vol. 93, no. 7, pp. 7625-7633, 1988. 


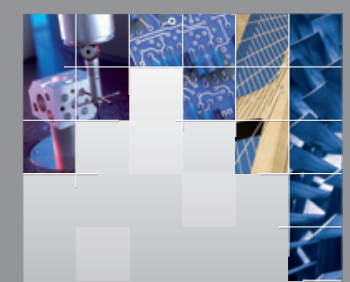

\section{Enfincering}
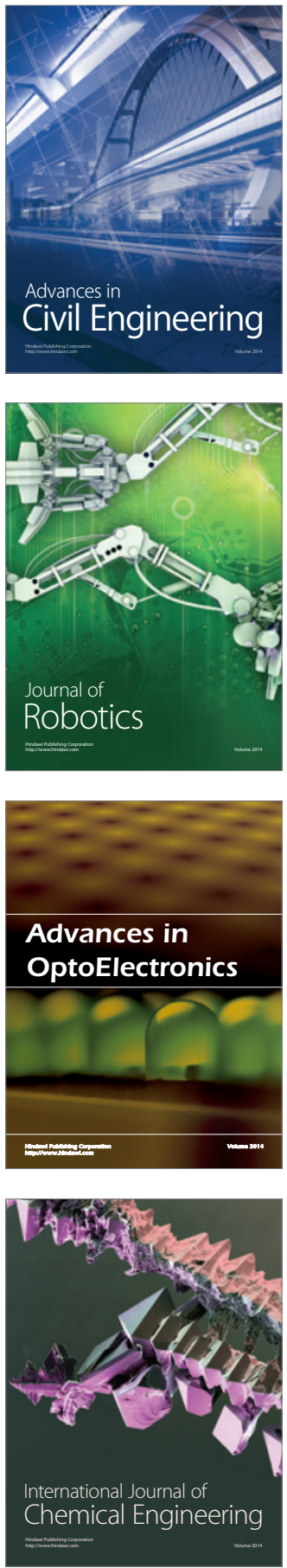

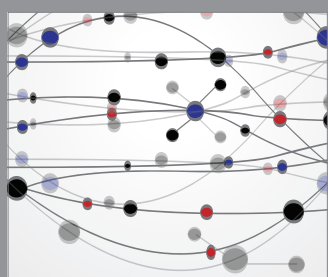

The Scientific World Journal

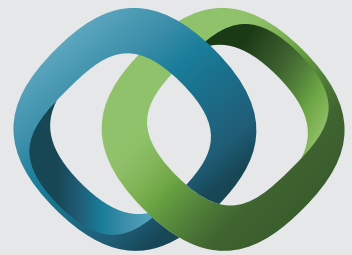

\section{Hindawi}

Submit your manuscripts at

http://www.hindawi.com
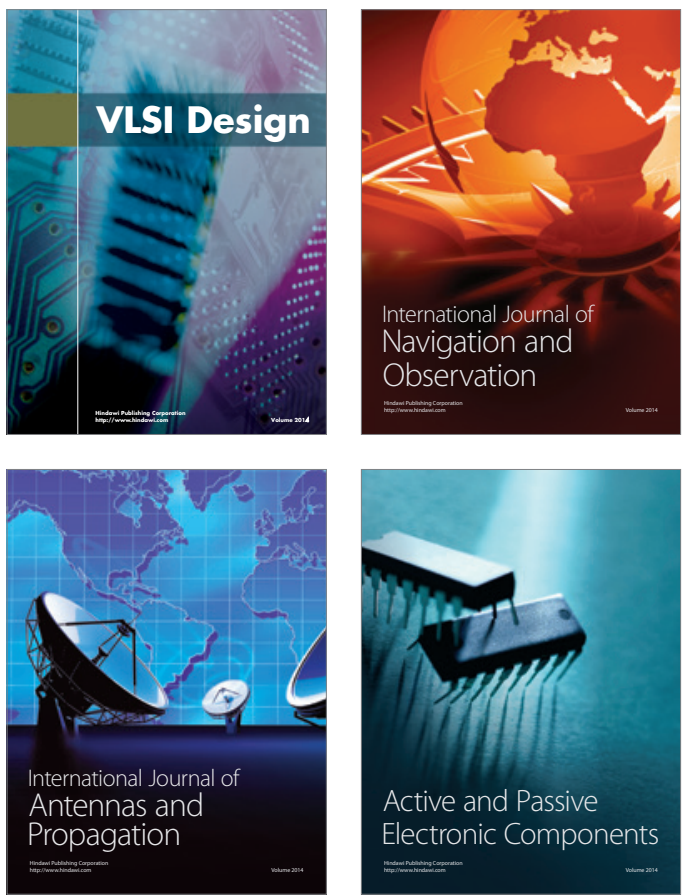
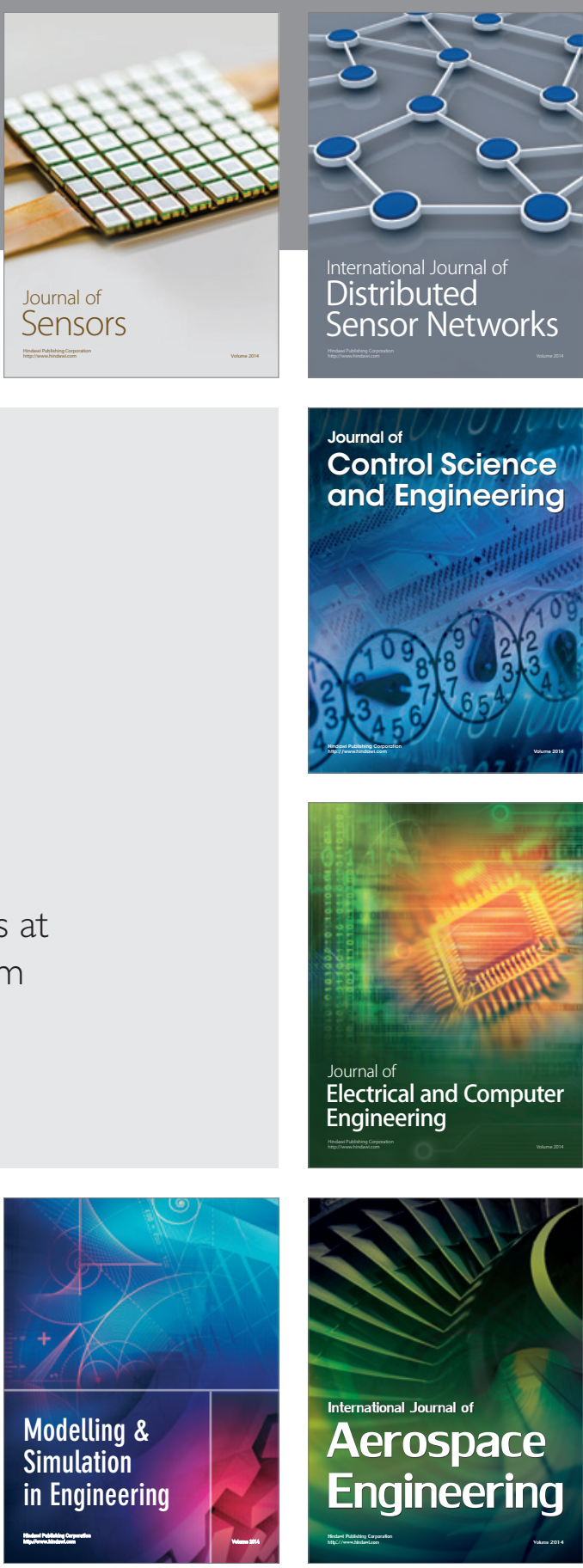

International Journal of

Distributed

Sensor Networks

Journal of

Control Science

and Engineering
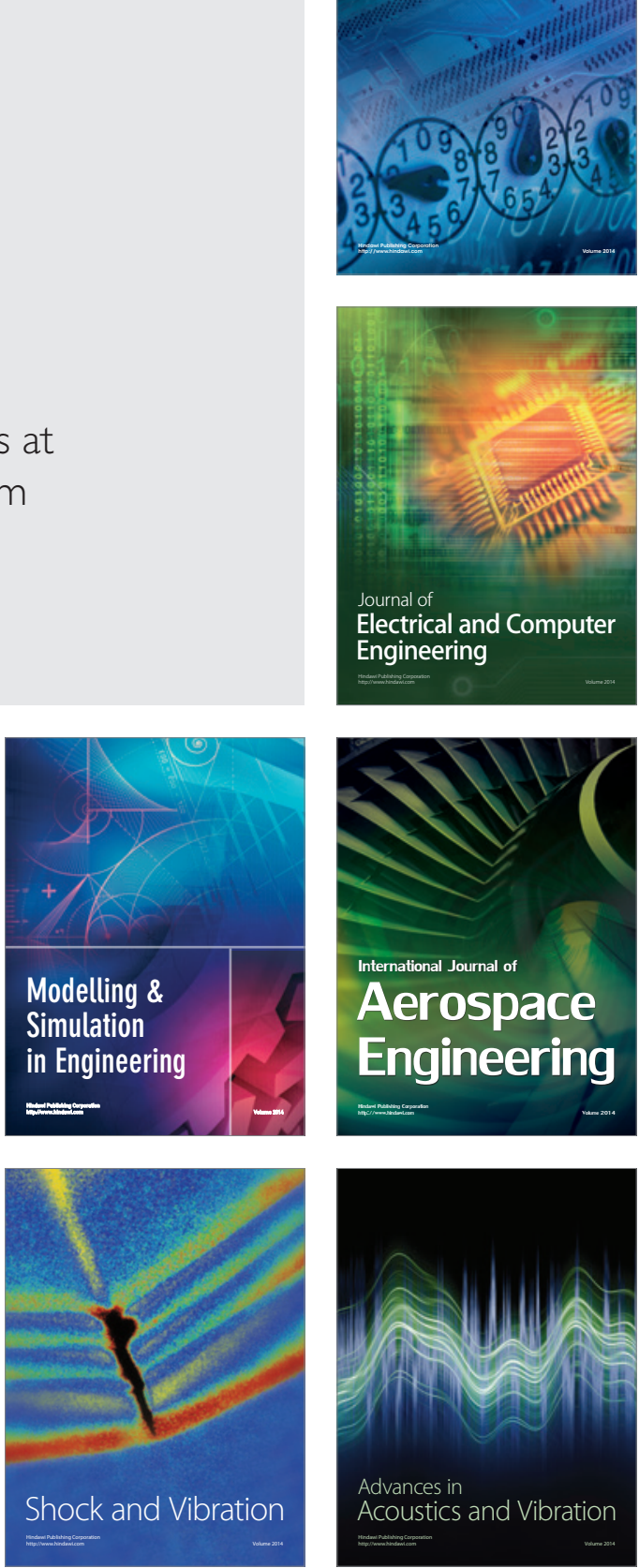